\title{
Centrilobular Endothelial Cell Injury by Diquat in the Selenium-Deficient Rat Liver
}

\author{
James B. Atkinson, Kristina E. Hill, and Raymond F. Burk \\ Division of Gastroenterology (KEH, RFB), Department of Medicine, Clinical Nutrition Research Unit (KEH, RFB), and \\ Department of Pathology (JBA, RFB), Vanderbilt University School of Medicine, Nashville, Tennessee
}

SUMMARY: Low doses of diquat cause massive liver necrosis and death of selenium-deficient rats within a few hours. Protection against this injury by selenium correlates with the presence of selenoprotein $\mathrm{P}$, an extracellular selenoprotein that associates with endothelial cells. Selenium-deficient rats were injected with diquat $(10 \mathrm{mg} / \mathrm{kg})$ and their livers were removed for light and electron microscopy at times up to 120 minutes after injection. Selenium-replete animals were studied before and 120 minutes after the same dose of diquat. With selenium deficiency, diquat caused injury to centrilobular endothelial cells. This injury was evident 20 minutes after diquat injection and progressed to cell loss at 60 minutes after diquat injection. At 120 minutes, endothelial cells were virtually absent from the centrilobular regions and hepatocytes in those areas were undergoing necrosis. Portal and midzonal areas remained normal in selenium-deficient livers, as did the entire liver lobule of selenium-replete rats. These findings indicate that the initial liver lesion in selenium-deficient rats given diquat is injury of the endothelial cells in the centrilobular region. After detachment of the endothelial cells, centrilobular hepatocytes undergo necrosis. We postulate that selenoprotein $\mathrm{P}$ protects the centrilobular endothelial cells against injury by oxidant molecules that result from diquat administration. (Lab Invest 2001, 81:193-200).

$T$ he bipyridylium redox-cycling compound diquat causes lipid peroxidation, liver necrosis, and renal tubular necrosis in selenium-deficient rats at doses that have no apparent effects on seleniumreplete animals (Burk et al, 1980). Within minutes of diquat administration, the plasma free $F_{2}$ isoprostane concentration rises, indicating the occurrence of lipid peroxidation. One to two hours after diquat, a rise in plasma alanine aminotransferase (ALT) activity indicates the occurrence of hepatocyte necrosis (Burk et al, 1995a). Animals die within several hours of diquat administration, and have plasma $\mathrm{F}_{2}$ isoprostane concentrations and ALT activities that are many-fold increased over control values (Burk et al, 1995a). In contrast to plasma $F_{2}$ isoprostanes, liver $F_{2}$ isoprostane concentrations increase only 4 -fold. The lack of quantitative correlation between liver necrosis and $F_{2}$ isoprostanes led to the suggestion that the direct liver injury caused by diquat takes place in a small hepatic compartment, perhaps at or near the hepatocyte membrane (Burk et al, 1995a).

Administration of physiologically relevant amounts of selenium 12 hours before administration of diquat prevents the lipid peroxidation and the liver necrosis (Burk et al, 1995a). This protection by selenium correlates with the presence of selenoprotein $\mathrm{P}$, an extracellular selenoprotein, and not with seleniumcontaining glutathione peroxidases in the cell or in the

Received October 2, 2000.

This work was supported by NIH grants ES 02497 and DK 26657.

Address reprint requests to: Dr. Raymond F. Burk, C-2104, Medical Center North, Vanderbilt Medical Center, Nashville, Tennessee 372322279.E-mail: raymond.burk@mcmail.vanderbilt.edu plasma. Selenoprotein $\mathrm{P}$ associates with endothelial cells in the liver and elsewhere (Burk et al, 1997). If it has an antioxidant role, selenoprotein $\mathrm{P}$ might be expected to protect endothelial cells because of this association. Hepatic endothelial cells are essential to the integrity of the liver but they constitute less than $5 \%$ of the liver mass.

The present ultrastructural study was carried out to characterize diquat injury of the liver in seleniumdeficient rats. In particular, a time course of injury was determined using electron microscopy to establish the sequence of events leading to massive liver necrosis.

\section{Results}

\section{Biochemical Characterization}

Selenium Status of Rats. Plasma glutathione peroxidase activity in the selenium-deficient rats (14 and 27 nmole of NADPH oxidized/[minute $\bullet \mathrm{ml}]$ ) was less than $2 \%$ of that in the controls (1300 and $1100 \mathrm{nmol}$ $\mathrm{NADPH}$ oxidized/[minute $\bullet \mathrm{ml}]$ ). Plasma selenoprotein $\mathrm{P}$ concentration in the selenium-deficient rats $(0.9$ and $0.9 \mu \mathrm{g} / \mathrm{ml}$ ) was $4 \%$ of the value in the control rats (19 and $29 \mu \mathrm{g} / \mathrm{ml})$. This indicates that the rats fed the selenium-deficient diet had severe selenium deficiency (Burk, 1987).

Plasma Measurements of Lipid Peroxidation and Liver Necrosis. Table 1 contains the individual ALT and free $F_{2}$ isoprostane values for each animal. Individual values are displayed because of the small number of animals studied. After diquat injection into seleniumdeficient animals, plasma free $\mathrm{F}_{2}$ isoprostane concentration was increased in one animal of each pair at 20 , 40 , and 60 minutes. In the 120-minute pair, one animal 
died just before blood was to have been taken, thus no values could be determined. The surviving 120-minute rat had greatly increased plasma free $F_{2}$ isoprostane and ALT values. Plasma free $F_{2}$ isoprostanes and ALT activities were unaffected by diquat in control animals (Table 1).

\section{Morphological Assessment}

Extent of Diquat Injury in Selenium-Deficient Liver. A preliminary light microscopic experiment was carried out to assess the extent of injury by diquat to selenium-deficient livers. Figure $1 \mathrm{~A}$ shows a centrilobular region of a liver from a selenium-deficient rat that had not received diquat. Its appearance is within normal limits. Figure 1B shows a centrilobular region of a selenium-deficient liver 120 minutes after the rat had received diquat. It is severely damaged. There is marked sinusoidal congestion and the demarcation between hepatocytes has become difficult to discern. Thus, diquat causes congestion of the central regions of the selenium-deficient liver and causes changes in the cell architecture.

Time Course in Control Animals. Animals were studied for 2 hours after administration of diquat. Two hours was chosen because a time course of injury (Burk et al, 1995a) had shown that lipid peroxidation occurred in the liver within minutes of diquat administration, but that hepatocyte necrosis had first occurred between 90 and 120 minutes. Thus, a 2-hour time course should allow detection of morphologic injury that precedes hepatocyte necrosis.

All four control livers were examined by light and electron microscopy. The livers were within normal limits when examined by light microscopy. By electron microscopy, they had a normal ultrastructure. The hepatic cords in the central regions (zone 3 ) consisted of normal-appearing hepatocytes that had the usual amount and arrangement of endoplasmic reticulum, lipid, and lysosomes. Intact endothelial cells lined the sinusoids in the central regions. These endothelial cells had the usual elongated shape, intact tight junctions, and normal fenestrations and a normal relationship to the space of Disse (Fig. 2, A and B). Kupffer cells were present on the sinusoidal side of the endothelium and had a normal appearance with clefted nuclei, numerous lysosomes, and pseudopodia. Thus, no degenerative changes were found by electron microscopy in control livers before or after diquat administration.

Time Course in Selenium-Deficient Animals. Livers from the two selenium-deficient rats that were not injected with diquat were indistinguishable from the control (selenium-replete) livers by light and electron microscopy.

Livers from selenium-deficient rats obtained 20 minutes after administration of diquat were normal by light microscopy, with no evidence of necrosis or degenerative changes. By electron microscopy, sinusoidal endothelial cells and hepatocytes in the portal (zone 1) and midzonal (zone 2) areas were normal, as were hepatocytes in the central regions (zone 3). Endothelial cells lining sinusoids in the central regions, however, had focal separation of tight junctions and were slightly displaced from the underlying hepatocytes along the space of Disse (Table 2; Fig. 3, A and B). Occasional endothelial cells in these areas had irregular shapes, with irregular nuclei and conversion of their elongated shape to a more polygonal shape. Rarely individual endothelial cells were absent from sinusoids in the central regions. Both livers had similar findings.

No abnormalities were detected by light microscopy in livers from selenium-deficient rats obtained 40 minutes after diquat injection. However, the central regions had ultrastructural changes involving the sinusoids, whereas portal and midzonal areas were ultrastructurally unremarkable. In the central regions, greater numbers of endothelial cells lining the sinusoids had irregular shapes at 40 minutes than at 20 minutes. Chromatin in the nuclei of some endothelial cells was irregularly clumped around the nuclear membrane, and small irregular cytoplasmic projections (blebs) were present in some endothelial cells (Table 2; Fig. 4, A and B). Single endothelial cells and small groups of endothelial cells were detached and separated from underlying hepatocytes. Kupffer cells in the portal and central regions appeared normal. Both livers had similar findings.

Mild and focal centrilobular vascular congestion was observed by light microscopy in some liver samples from selenium-deficient rats 60 minutes after diquat administration. However, more striking changes were evident by electron microscopy, which were confined to the central regions. Virtually all

Table 1. Biochemical Evidence of Liver Injury and Lipid Peroxidation by Diquat in Selenium-Deficient and Control Rats

\begin{tabular}{|c|c|c|c|c|}
\hline \multirow[b]{2}{*}{$\begin{array}{l}\text { Minutes after } \\
\text { diquat injection }\end{array}$} & \multicolumn{2}{|c|}{ Selenium-deficient } & \multicolumn{2}{|c|}{ Control } \\
\hline & $\begin{array}{c}\text { ALT } \\
(\mathrm{mU} / \mathrm{ml} \text { plasma })\end{array}$ & $\begin{array}{c}\mathrm{F}_{2} \text { isoprostanes } \\
\text { (ng/ml plasma) }\end{array}$ & $\begin{array}{c}\text { ALT } \\
(\mathrm{mU} / \mathrm{ml} \text { plasma })\end{array}$ & $\begin{array}{l}\mathrm{F}_{2} \text { isoprostanes } \\
\text { (ng/ml plasma) }\end{array}$ \\
\hline 0 & 48,48 & $0.05,0.05$ & 29,29 & $0.04,0.04$ \\
\hline 20 & 36,39 & $0.04,0.15$ & - & - \\
\hline 40 & 63,46 & $0.05,0.45$ & - & - \\
\hline 60 & 32,32 & $0.93,0.07$ & - & - \\
\hline 120 & 4400 , died & 2.0, died & 27,24 & $0.06,0.05$ \\
\hline
\end{tabular}

ALT, alanine aminotransferase. 

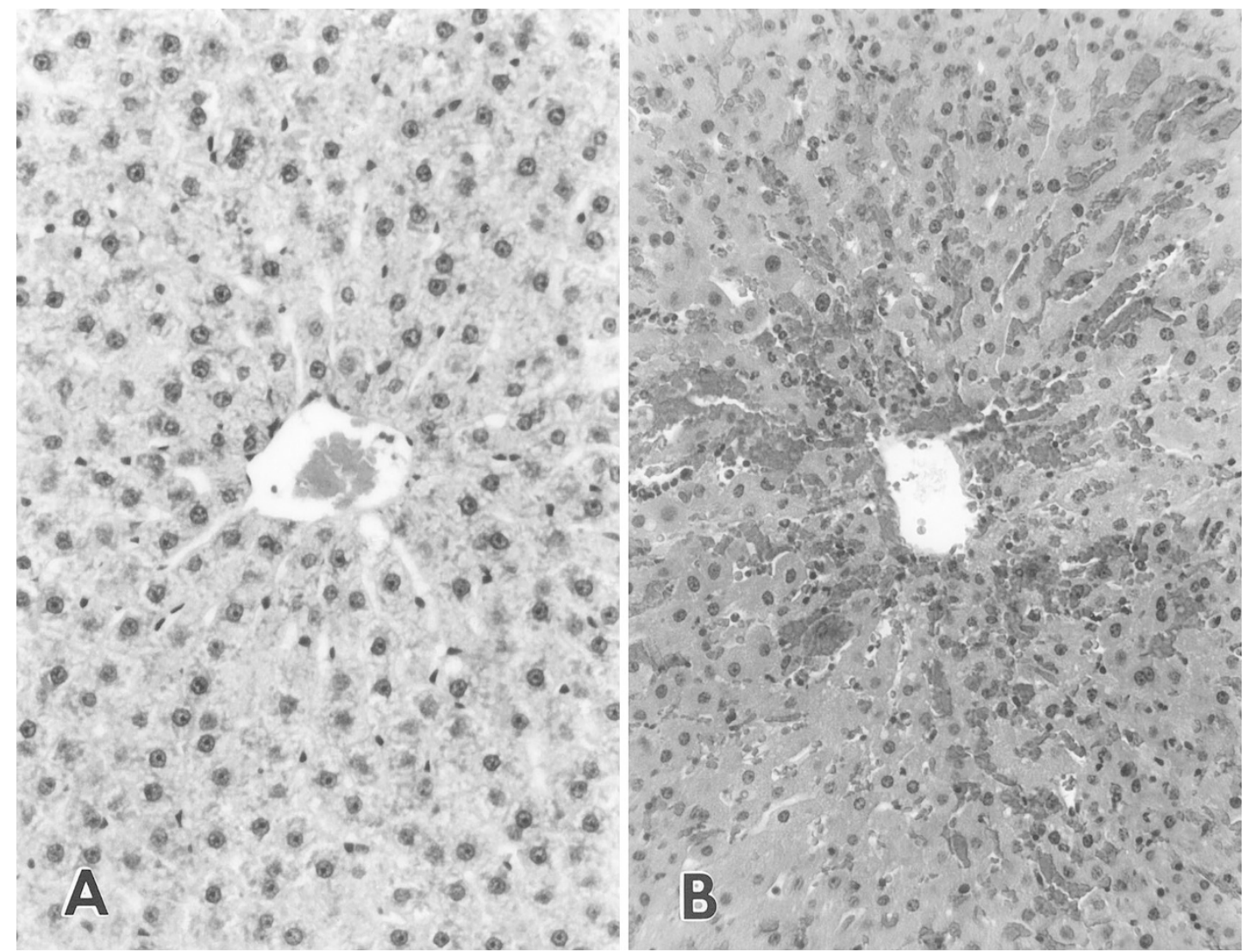

Figure 1.

Diquat injury of selenium-deficient liver. A, Light micrograph (hematoxylin and eosin, original magnification, $\times 256$ ) of a centrilobular area from a selenium-replete rat that had received diquat 120 minutes before the liver was removed. It shows no abnormalities. B, Light micrograph (hematoxylin and eosin, original magnification, $\times 256$ ) of a centrilobular area from a selenium-deficient rat that received diquat (10 mg/kg intraperitoneally) 120 minutes before the liver was removed. There is marked vascular congestion, and hepatocytes near the central vein seem to be disrupted. The plasma alanine aminotransferase (ALT) was $22,000 \mathrm{mU} / \mathrm{ml}$.

endothelial cells lining sinusoids in the central regions had abnormal shapes, and some of them appeared to be disrupted (Table 2; Fig. 5). Large areas were devoid of endothelial cells, and small fragments of membrane-bound cytoplasm and cellular debris were present in the vascular space. Although most hepatocytes in the central regions were ultrastructurally normal, rare hepatocytes had breaks in their plasma membranes. Endothelial cells and hepatocytes in the portal and midzonal areas appeared normal by electron microscopy. Both livers had similar findings.

Light microscopic examination of liver samples from selenium-deficient rats obtained 120 minutes after injection of diquat revealed an apparent loss of endothelial cells in the central regions, with swelling noted in the remaining centrilobular endothelial cells. Mild to moderate centrilobular vascular congestion was observed. Scattered focal groups of hepatocytes had fatty metamorphosis. By electron microscopy, endothelial cells were virtually absent from the central regions (Table 2; Fig. 6). Cellular debris was present in the vascular spaces. Mitochondria in hepatocytes were swollen. Some centrilobular hepatocytes had disrupted plasma membranes with loss of surface microvilli. Autophagolysosomes were present within their cytoplasm. These changes were not observed in the portal and midzonal areas. The two livers had similar findings.

\section{Discussion}

This study demonstrates that the liver injury caused by diquat administration to selenium-deficient rats takes place in the centrilobular region with ultrastructural evidence of endothelial cell injury preceding evidence of hepatocyte injury. Twenty minutes after diquat injection, endothelial cells lining sinusoids in the central regions had developed irregular shapes and had begun to separate from each other and from underlying hepatocytes. Progressive deterioration of endothelial cell morphology continued until the sinusoids in the central areas were devoid of endothelial cells at 120 minutes after diquat administration.

Hepatocytes remained morphologically normal until 60 minutes after diquat injection, when breaks in their plasma membranes were occasionally found. This progressed to a more extensive disruption of the plasma membrane at 120 minutes after injection. Swelling of mitochondria occurred as the hepatocytes became necrotic.

These changes were confined to the central regions (zone 3). Portal areas (zone 1) and midzonal areas 

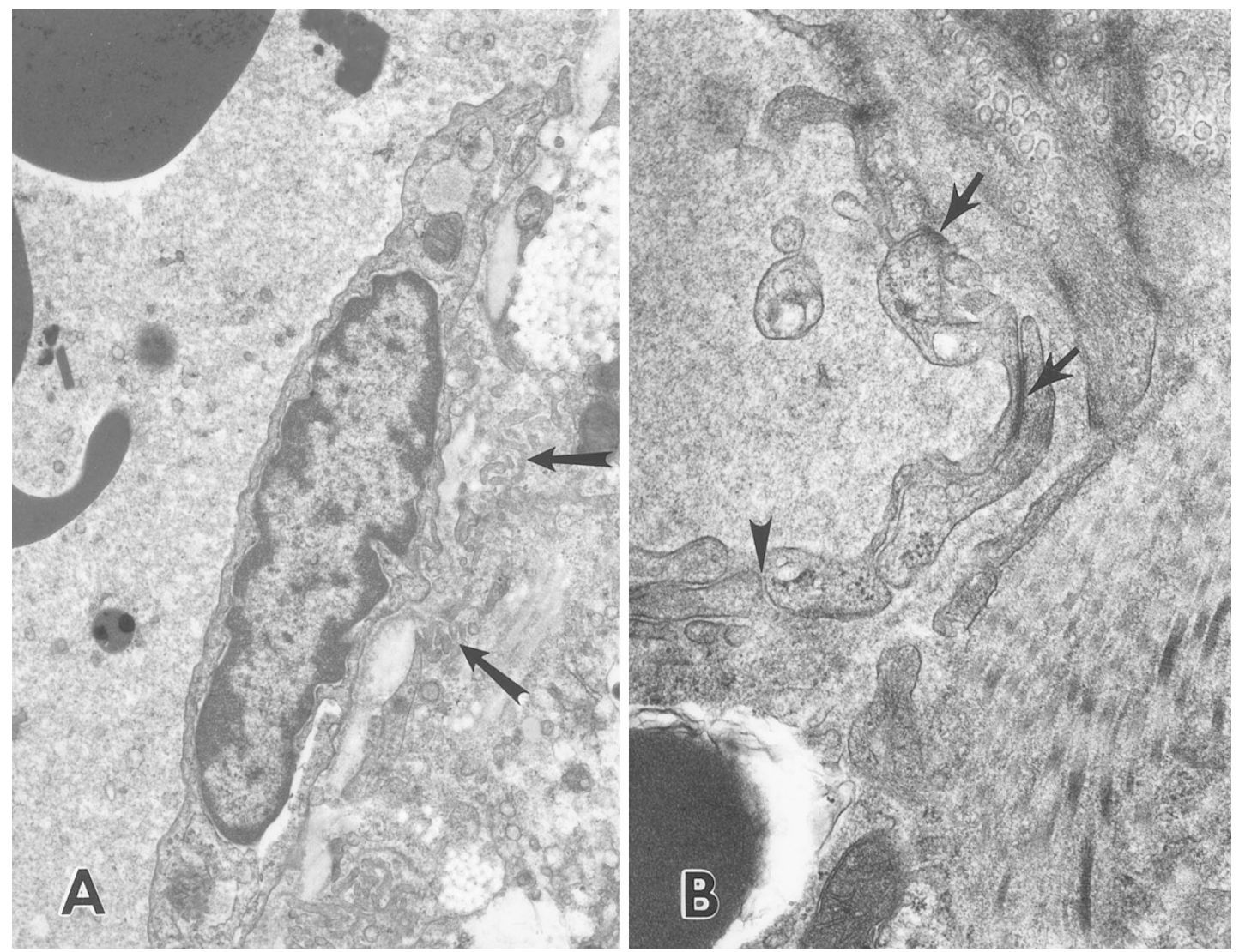

\section{Figure 2.}

Sinusoid in centrilobular region of liver from a selenium-replete rat 120 minutes after diquat administration. A, The endothelial cell that lines this central sinusoid has the usual elongated shape. Its nucleus has a normal shape and chromatin pattern. Microvilli from underlying hepatocytes extend into the space of Disse (arrows) (original magnification, $\times 8100)$. B, Higher magnification of endothelial cells in a central sinusoid, showing tight junctions (arrows) and fenestrations $($ arrowhead) (original magnification, $\times 20,500)$.

(zone 2) were ultrastructurally normal. Therefore, this lesion is centrilobular and begins with injury to the endothelial cells.

A previous report has described congestion of the liver and failure of the blood to clot in seleniumdeficient animals that survived for several hours after diquat administration (Burk et al, 1980). Both of these manifestations could be explained by endothelial cell loss in the centrilobular regions. Endothelial cell loss would expose a surface that activates blood clotting, causing consumption of coagulation factors. It would also increase resistance to blood flow in the sinusoids, leading to congestion with swelling of the liver, as demonstrated in Figure 1B. Thus, the ultrastructural lesion described in these studies is a plausible cause of several observed manifestations of diquat injury in selenium-deficient rats.

The plasma free $F_{2}$ isoprostane concentration reflects release of these compounds from tissues throughout the body (Burk et al, 1995a; Morrow et al, 1990). At 20, 40, and 60 minutes after diquat injection, one of each pair of selenium-deficient rats had a normal plasma free $F_{2}$ isoprostane concentration whereas the other rat had an elevated value (Table 1). Both livers at each time point had similar ultrastructural evidence of endothelial cell damage. This suggests that the process of injury to the hepatic endo- thelial cells does not produce enough $\mathrm{F}_{2}$ isoprostanes to raise plasma free $F_{2}$ isoprostane levels. Potential explanations for this would be that the amount of lipid peroxidation occurring in the endothelial cell is small or that the mechanism of endothelial cell injury does not involve lipid peroxidation. Another implication of these findings is that most of the plasma free $F_{2}$ isoprostanes found in this model arise in extrahepatic tissues such as the kidneys (Burk et al, 1995b).

Diquat is a redox-cycling compound. It accepts an electron from NADPH-cytochrome $\mathrm{P}-450$ reductase in the endoplasmic reticulum of the hepatocyte (Farrington et al, 1973) and thereby becomes a free radical. The diquat radical recycles to the non-radical form by donating its unpaired electron to molecular oxygen $\left(\mathrm{O}_{2}\right)$, producing superoxide $\left(\mathrm{O}_{2}{ }^{-}\right)$. Thus, diquat promotes the formation of superoxide from $\mathrm{O}_{2}$.

In well-oxygenated liver cells, the diquat radical encounters $\mathrm{O}_{2}$ within the hepatocyte, and superoxide dismutase would be expected to efficiently remove the resulting superoxide. However, in vitro studies show that when the oxygen tension is very low the diquat radical can diffuse across the hepatocyte membrane to the extracellular space (Cornu et al, 1993). This implies that diquat radicals formed in the lowoxygen centrilobular regions of the liver can exit the cell and be available to react with $\mathrm{O}_{2}$ in the space of 

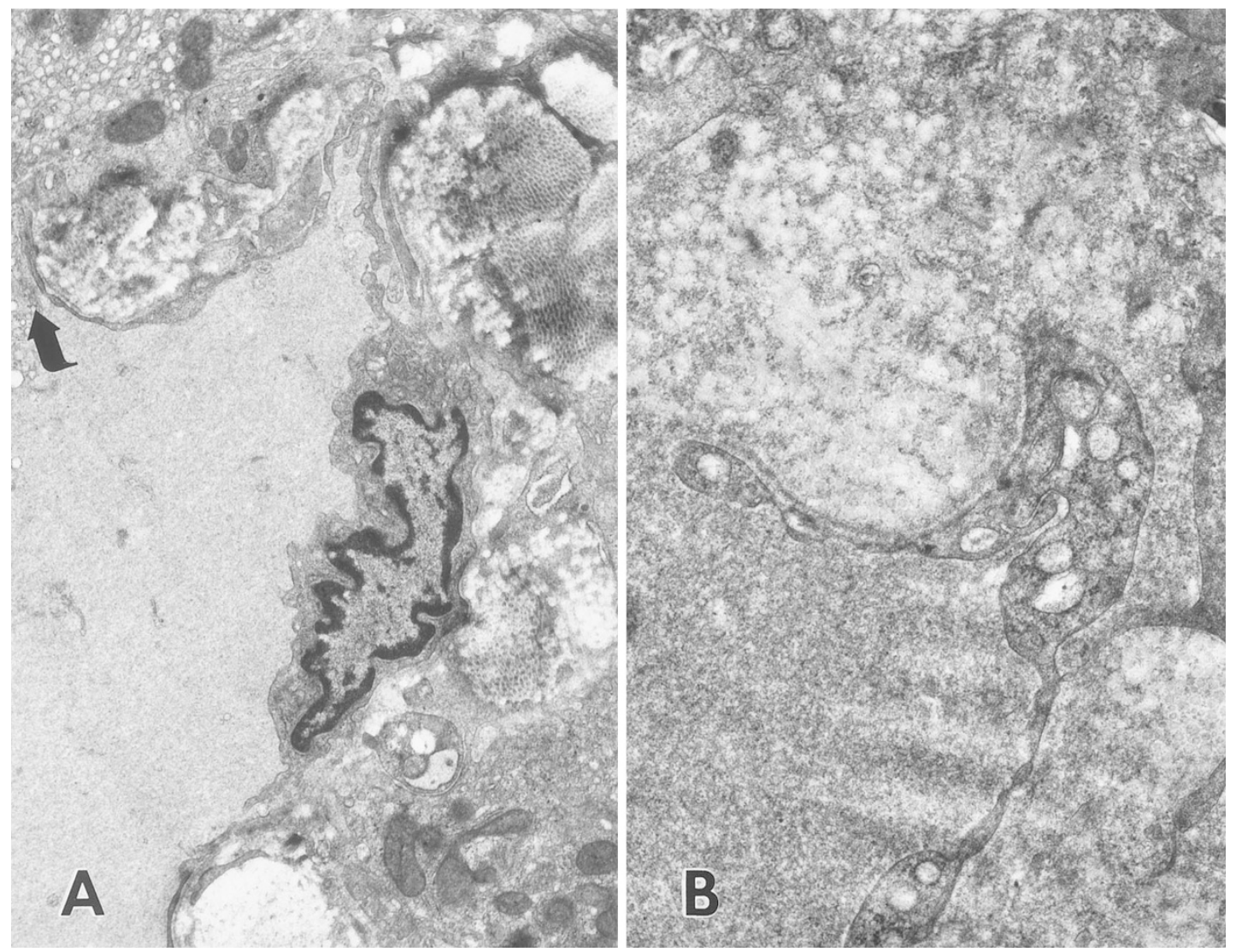

\section{Figure 3.}

Sinusoid in centrilobular region of liver from a selenium-deficient rat 20 minutes after diquat administration. A, The endothelial cell shown here has an irregularly shaped nucleus. There is focal loss of an adjacent endothelial cell process (arrow) (original magnification, $\times 6850$ ). B, This higher magnification shows loss of continuity of endothelial cells with displacement of the endothelial cell process away from the space of Disse (original magnification, $\times 16,000$ )

Disse. The fate of superoxide at this extracellular location would likely be different from that of intracellular superoxide. In the extracellular space, superoxide dismutase activity is relatively low and nitric oxide produced by the endothelial cells is relatively abundant. Nitric oxide and superoxide react rapidly to form the highly oxidizing compound peroxynitrite (ONOO-) (Koppenol et al, 1992). It seems likely that peroxynitrite would be formed in the space of Disse under these conditions.

Peroxynitrite serves in signaling under physiologic circumstances (Patel et al, 2000). However, when it is over-produced, its oxidizing nature makes it toxic $(\mathrm{Hu}$ et al, 1994). Thus, we postulate that over-production of peroxynitrite in the space of Disse leads to the endothelial cell injury demonstrated in this report. This hypothesis can explain the observation that hyperbaric oxygen treatment lengthens survival of diquattreated selenium-deficient rats (Burk and Lane 1983). Increasing the oxygen tension in the hepatocytes would be expected to increase diquat radical- $\mathrm{O}_{2}$ reactions inside the cell and to decrease the diffusion of diquat radicals across the hepatocyte membrane.

Why does the injury not occur in rats that are selenium replete? Peroxynitrite can be detoxified by reaction with selenium compounds (Assmann et al, 1998; Padmaja et al, 1996). Evidence suggests that selenoprotein P (Arteel et al, 1998) and glutathione peroxidase (Sies et al, 1997) can detoxify peroxynitrite. A previous report linked the protection by selenium against diquat liver injury with the presence of selenoprotein $\mathrm{P}$ (Burk et al, 1995a). The present report indicates that the earliest damage found in the liver after diquat administration is endothelial cell injury. Selenoprotein $\mathrm{P}$ associates strongly with hepatic sinusoidal endothelial cells (Burk et al, 1997) and we postulate that it detoxifies peroxynitrite in that location.

Other reports of diquat (and paraquat) liver injury have appeared. None of the other models studied is strictly comparable with the model studied here. Several investigators showed that specific strains of rats develop liver injury when given relatively high doses of diquat (Smith et al, 1985). That injury was not related to selenium status.

Mice with homozygous null mutation for the selenoenzyme cellular glutathione peroxidase (GSHPx-1) have been studied by two groups. One group showed that the knockout mice were more sensitive to doses of paraquat in the $50 \mathrm{mg} / \mathrm{kg}$ of body weight-and-up range than were the wild-type mice (Cheng et al, 1998). However, the end-point of that study was death, and the livers were not evaluated. Knockout mice given $12.5 \mathrm{mg}$ of paraquat $/ \mathrm{kg}$ of body weight lived 2 weeks and had no apparent lesions at sacrifice. This dose of paraquat is slightly larger than the 10 

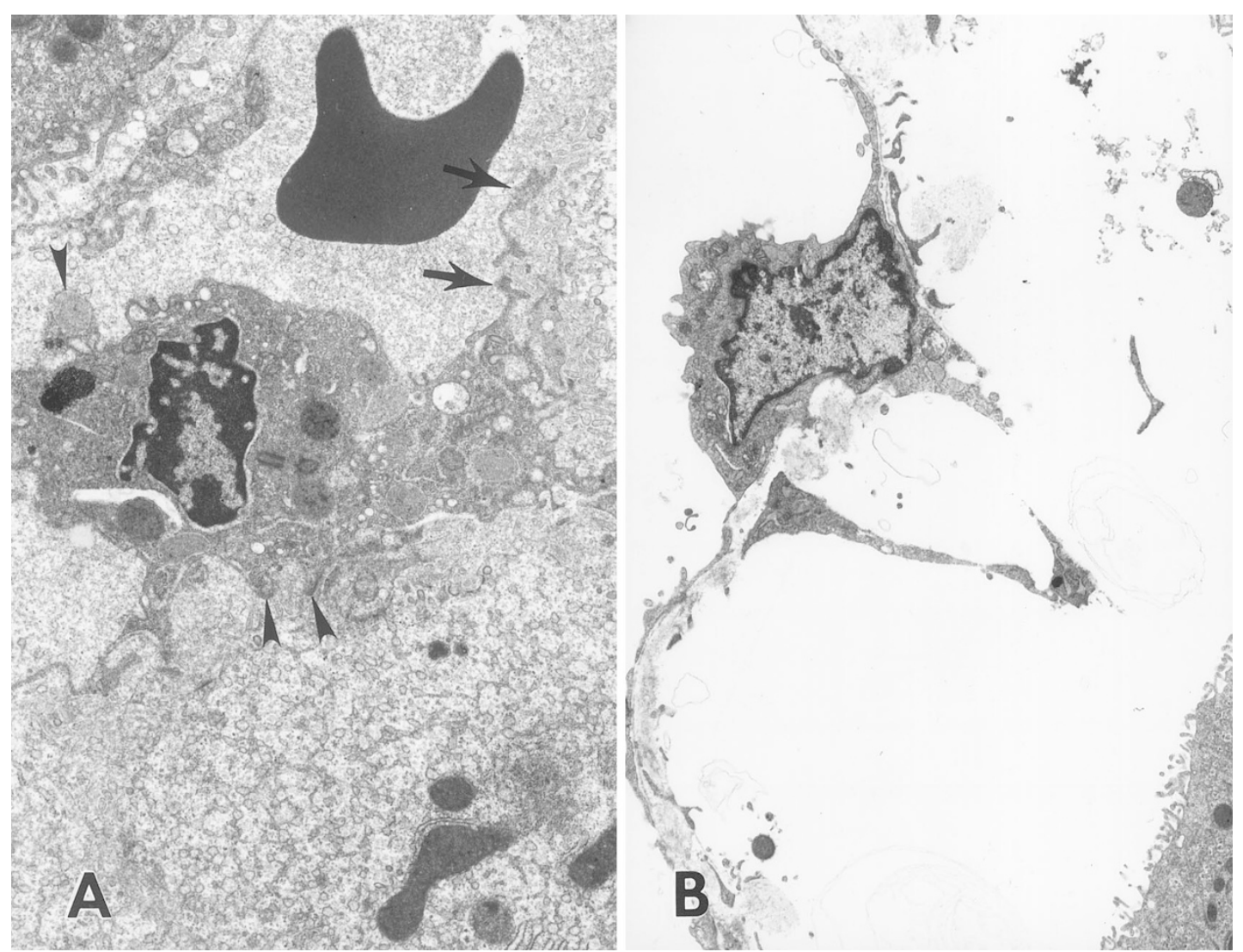

Figure 4.

Sinusoid in centrilobular region of liver from a selenium-deficient rat 40 minutes after diquat administration. A, The endothelial cell shown here has an abnormal shape with loss of the normal elongated profile. There is marked condensation of chromatin around the edge of the nucleus. Irregular, thin cytoplasmic processes extend over the space of Disse (arrows) and cytoplasmic blebs can be seen (arrowheads) (original magnification, $\times 6850$ ). B, The endothelial cell in this photo has a markedly abnormal shape and is widely separated from the underlying hepatocyte (original magnification, $\times 3900$ ).

Table 2. Summary of Ultrastructural Findings in Selenium-Deficient Rat Livers after Diquat Injection

\begin{tabular}{|c|c|c|c|}
\hline \multirow{2}{*}{$\begin{array}{l}\text { Minutes } \\
\text { after } \\
\text { injection }\end{array}$} & \multicolumn{2}{|l|}{ Endothelial cells } & \multirow{2}{*}{$\begin{array}{l}\text { Hepatocytes } \\
\text { Central region }\end{array}$} \\
\hline & Central region & $\begin{array}{l}\text { Portal and } \\
\text { midzonal regions }\end{array}$ & \\
\hline 20 & $\begin{array}{l}\text { Occasional cells with irregular shapes, focal } \\
\text { separation of tight junctions, and slight } \\
\text { displacement from the space of Disse, rare } \\
\text { loss of endothelial cells }\end{array}$ & Normal & Normal \\
\hline 40 & $\begin{array}{l}\text { Many cells with irregular shapes, detachment } \\
\text { of cells (single or in small groups) }\end{array}$ & Normal & Normal \\
\hline 60 & $\begin{array}{l}\text { Remaining cells had abnormal shapes, cells } \\
\text { virtually absent from some central regions, } \\
\text { cellular debris in vascular spaces }\end{array}$ & Normal & $\begin{array}{c}\text { Focal breaks in plasma } \\
\text { membrane }\end{array}$ \\
\hline 120 & $\begin{array}{l}\text { Endothelial cells absent, cellular debris in } \\
\text { vascular spaces }\end{array}$ & Normal & $\begin{array}{c}\text { Disruption of plasma membrane, } \\
\text { swollen mitochondria, } \\
\text { autophagosomes }\end{array}$ \\
\hline
\end{tabular}

$\mathrm{mg} / \mathrm{kg}$ of body weight dose of diquat that we used in our study. The other group studying knockout mice found that all knockout mice given $30 \mathrm{mg}$ of paraquat/kg of body weight died within 5 hours but only 1 of 11 rats given $10 \mathrm{mg}$ of paraquat/ $\mathrm{kg}$ of body weight died (de Haan et al, 1998). This group also did not evaluate specific organ damage or markers of lipid peroxidation. Thus, care must be taken in comparing studies of bipyridylium toxicity with one another because conditions of the studies vary greatly, as do the manifestations of toxicity used as endpoints.

In conclusion, this study has demonstrated that diquat liver damage in selenium-deficient rats begins with injury of centrilobular endothelial cells. Loss of 


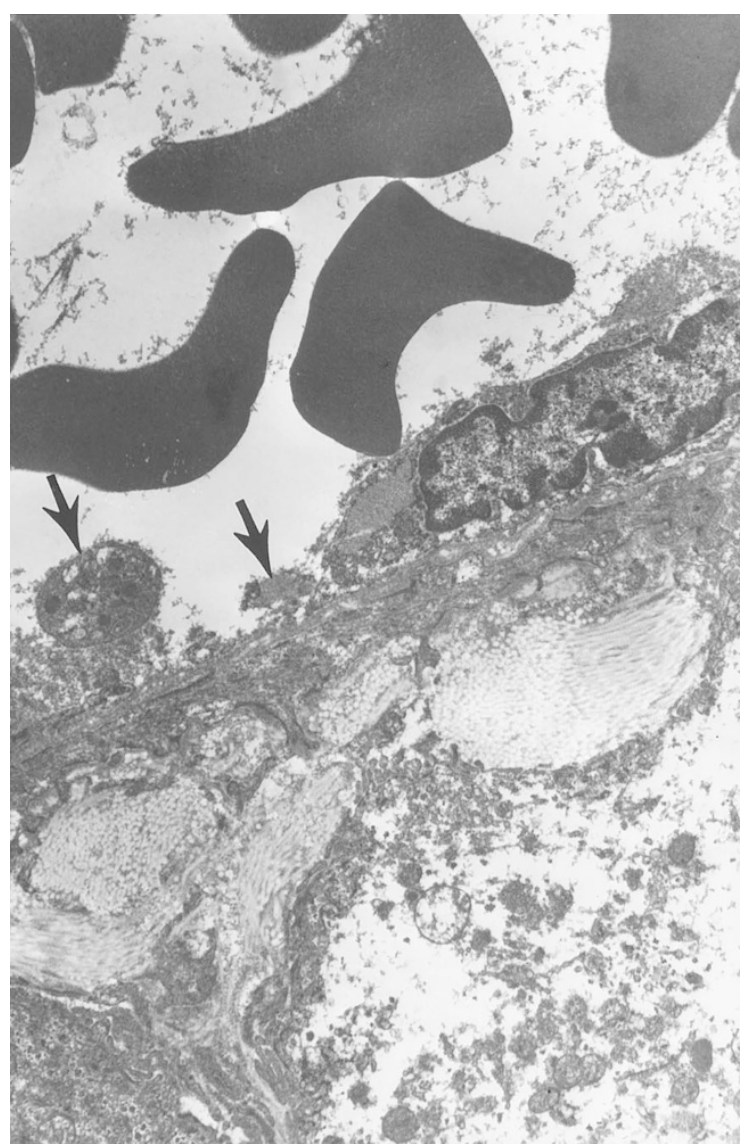

Figure 5.

Central vein of liver from a selenium-deficient rat 60 minutes after diquat administration. This image shows a rare intact remaining endothelial cell lining the central vein. It has lost its normal long cytoplasmic processes, and cytoplasmic blebs and debris (arrows) overlie the space of Disse (original magnification, $\times 4550$ )

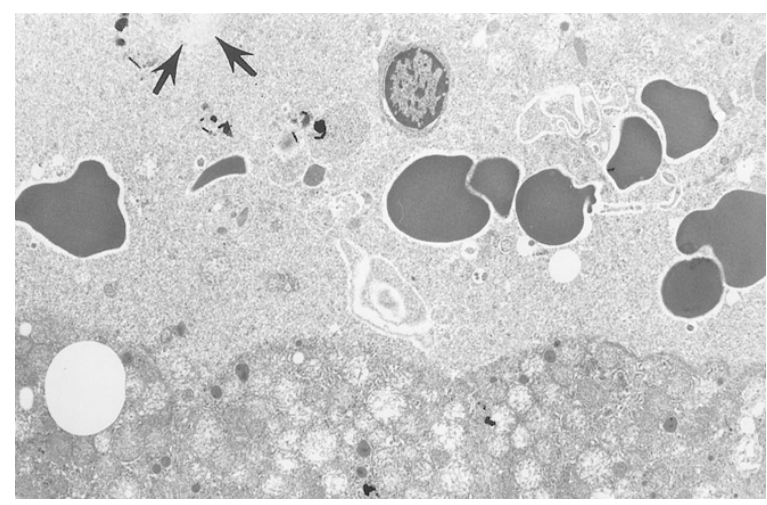

Figure 6.

Sinusoid in centrilobular region of liver from a selenium-deficient rat 120 minutes after diquat administration. Endothelial cells are absent. Most hepatocyte mitochondria are swollen. The vascular space contains pieces of cytoplasm, amorphous debris, and collagen fibrils (arrows) (original magnification, $\times 3200)$.

these endothelial cells is followed by necrosis of underlying hepatocytes. The establishment of this sequence of events strengthens the hypothesis that selenoprotein $\mathrm{P}$ protects the endothelial cells against oxidant injury.

\section{Materials and Methods}

\section{Animals}

Weanling male Sprague-Dawley rats were purchased from Harlan Sprague-Dawley (Indianapolis, Indiana) and housed in an American Association for Accreditation of Laboratory Animal Care-approved animal facility with 12-hour alternating light and dark periods. They were fed a Torula yeast-based diet (Burk, 1987) and provided tap water ad libitum. In its basal form, the diet was selenium-deficient. The control diet was the basal diet with $0.25 \mathrm{mg}$ of selenium as sodium selenate added per kilogram. Animals were fed the diets for 9 months before they were studied.

Rats were given intraperitoneal injections of diquat dibromide, $10 \mathrm{mg} / \mathrm{kg}$ (Chem Service, West Chester, New York). This dose was chosen because it had been found in our experiments to produce lipid peroxidation and liver necrosis in selenium-deficient rats in a reliable manner. Half the dose, $5 \mathrm{mg} / \mathrm{kg}$, produced lipid peroxidation and liver necrosis in some rats but not in all rats. Selenium-replete animals given $10 \mathrm{mg} / \mathrm{kg}$ of diquat dibromide did not manifest any injury. Thus, the dose of $10 \mathrm{mg}$ of diquat dibromide/ $\mathrm{kg}$ of body weight was chosen because it reliably elicited the injury to be studied in selenium-deficient rats but did not injure selenium-replete rats.

Selenium-deficient animals were killed before diquat injection and at 20,40,60, and 120 minutes after injection. Controls were killed before diquat injection and at 120 minutes after injection. Two animals were studied in each experimental group. Rats were anesthetized with intraperitoneal injections of pentobarbital sodium ( $65 \mathrm{mg} / \mathrm{kg}$ of body weight) and exsanguinated by removal of blood from the aortic bifurcation. Blood was mixed with EDTA ( $1 \mathrm{mg} / \mathrm{ml}$ of blood) to prevent coagulation and plasma was separated by centrifugation. Liver samples were taken immediately and put into $10 \%$ buffered formalin for light microscopy and into phosphate-buffered $2 \%$ glutaraldehyde for electron microscopy.

\section{Assays}

In the rats that did not receive diquat, plasma selenoprotein $\mathrm{P}$ was measured by radioimmunoassay (Burk et al, 1991) and plasma glutathione peroxidase was measured using a modification of the coupled assay with hydrogen peroxide as substrate (Lawrence and Burk, 1976). Plasma ALT was measured using a kit (ALT 10, Sigma Chemical Company, St. Louis, Missouri). Plasma free $F_{2}$ isoprostanes were determined by gas chromatography/negative-ion chemical ionization mass spectrometry after purification and derivatization (Morrow et al, 1990; Wendelborn et al, 1990).

\section{Morphologic Studies}

Samples for electron microscopy were fixed for 48 hours in glutaraldehyde, washed in phosphatebuffered $7.5 \%$ sucrose, and postfixed in phosphatebuffered $2 \%$ osmium tetroxide for 1 hour (Atkinson et 
al, 1981). The samples were stained with $1 \%$ uranyl acetate, dehydrated in a graded series of alcohol, cleared in propylene oxide, and embedded in an araldite resin mixture. Thick sections $(1.5 \mu \mathrm{m})$ stained with toluidine blue were examined by light microscopy, and appropriate areas were chosen for thin (less than $1 \mu \mathrm{m})$ sections.

\section{Acknowledgement}

The authors are grateful to Amy K. Motley for performing the $\mathrm{F}_{2}$ isoprostane measurements.

\section{References}

Arteel GE, Mostert V, Oubrahim H, Briviba K, Abel J, and Sies $H$ (1998). Protection by selenoprotein $P$ in human plasma against peroxynitrite-mediated oxidation and nitration. Biol Chem 379:1201-1205.

Assmann A, Briviba K, and Sies H (1998). Reduction of methionine selenoxide to selenomethionine by glutathione. Arch Biochem Biophys 349:201-203.

Atkinson JB, Swift LL, and LeQuire VS (1981). Myotonia congenita. A histochemical and ultrastructural study in the goat: Comparison with abnormalities found in human myotonia dystrophica. Am J Pathol 102:324-335.

Burk RF (1987). Production of selenium deficiency in the rat. Methods Enzymol 143:307-313.

Burk RF, Hill KE, Awad JA, Morrow JD, Kato T, Cockell KA, and Lyons PR (1995a). Pathogenesis of diquat-induced liver necrosis in selenium-deficient rats. Assessment of the roles of lipid peroxidation by measurement of $F_{2}$ isoprostanes. Hepatology 21:561-569.

Burk RF, Hill KE, Awad JA, Morrow JD, and Lyons PR (1995b). Liver and kidney necrosis in selenium-deficient rats depleted of glutathione. Lab Invest 72:723-730.

Burk RF, Hill KE, Boeglin ME, Ebner FF, and Chittum HS (1997). Selenoprotein P associates with endothelial cells in rat tissues. Histochem Cell Biol 108:11-15.

Burk RF, Hill KE, Read R, and Bellew T (1991). Response of rat selenoprotein $P$ to selenium administration and fate of its selenium. Am J Physiol 261:E26-E30.

Burk RF and Lane JM (1983). Modification of chemical toxicity by selenium deficiency. Fundam Appl Toxicol 3:218221.

Burk RF, Lawrence RA, and Lane JM (1980). Liver necrosis and lipid peroxidation in the rat due to paraquat and diquat administration. J Clin Invest 65:1024-1031.

Cheng W-H, Ho YS, Valentine BA, Ross DA, Combs GF Jr, and Lei XG (1998). Cellular glutathione peroxidase is the mediator of body selenium to protect against paraquat lethality in transgenic mice. J Nutr 128:1070-1076.
Cornu MC, Moore GA, Nakagawa Y, and Moldeus P (1993). Ascorbic acid uptake by isolated rat hepatocytes: Stimulatory effect of diquat, a redox cycling compound. Biochem Pharmacol 46:1333-1338.

de Haan JB, Bladier C, Griffiths P, Kelner M, O'Shea RD, Cheung NS, Bronson RT, Silvestro MJ, Wild S, Zheng SS, Beart PM, Hertzog PJ, and Kola I (1998). Mice with a homozygous null mutation for the most abundant glutathione peroxidase, Gpx1, show increased susceptibility to the oxidative stress-inducing agents paraquat and hydrogen peroxide. J Biol Chem 273:22528-22536.

Farrington JA, Ebert M, Land EJ, and Fletcher K (1973). Bipyridylium quaternary salts and related compounds. V. Pulse radiolysis studies of the reaction of paraquat with oxygen. Implications for the mode of action of bipyridyl herbicides. Biochim Biophys Acta 31:372-381.

Hu P, Ischiropoulos H, Beckman JS, and Matalon S (1994). Peroxynitrite inhibition of oxygen consumption and sodium transport in alveolar type II cells. Am J Physiol 266:L628L634.

Koppenol WH, Moreno JJ, Pryor WA, Ischiropoulos $\mathrm{H}$, and Beckman JS (1992). Peroxynitrite, a cloaked oxidant formed by nitric oxide and superoxide. Chem Res Toxicol 5:834842.

Lawrence RA and Burk RF (1976). Glutathione peroxidase activity in selenium-deficient rat liver. Biochem Biophys Res Commun 71:952-958.

Morrow JD, Hill KE, Burk RF, Nammour TM, Badr KF, and Roberts LJ (1990). A series of prostaglandin $F_{2}$-like compounds are produced in vivo in humans by a noncyclooxygenase, free radical-catalyzed mechanism. Proc Natl Acad Sci USA 87:9383-9387.

Padmaja S, Squadrito GL, Lemercier JN, Cueto R, and Pryor WA (1996). Rapid oxidation of DL-selenomethionine by peroxynitrite. Free Radic Biol Med 21:317-322.

Patel RP, Moellering D, Murphy-Ullrich J, Jo H, Beckman JS, and Darley-Usmar VM (2000). Cell signaling by reactive nitrogen and oxygen species in atherosclerosis. Free Radic Biol Med 28:1780-1794.

Sies H, Sharov VS, Klotz LO, and Briviba K (1997). Glutathione peroxidase protects against peroxynitrite-mediated oxidations. A new function for selenoproteins as peroxynitrite reductase. J Biol Chem 272:27812-27817.

Smith CV, Hughes H, Lauterburg BH, and Mitchell JR (1985). Oxidant stress and hepatic necrosis in rats treated with diquat. J Pharmacol Exp Ther 235:172-177.

Wendelborn DF, Morrow JD, and Roberts LJ (1990). Quantification of $9 a, 11 b-P F_{2}$ by stable isotope dilution mass spectrometry. Methods Enzymol 187:51-62. 